\title{
A Unified Theory and Test of Extended Immediate Deterrence
}

\author{
Curtis S. Signorino University of Rochester \\ Ahmer Tarar Texas A\&M University
}

\begin{abstract}
We present a unified theory and test of extended immediate deterrence-unified in the sense that we employ our theoretical deterrence model as our statistical model in the empirical analysis. The theoretical model is a straightforward formalization of the deterrence logic in Huth (1988) and Huth and Russett (1984), coupled with private information concerning utilities. Our statistical analysis suggests that the attacker and defender's decisions are influenced by the balance of forces, nuclear weapons, defender-protege military alliances, arms transfers, and trade, as well as the regime types of those involved. Many of these findings contradict previous research by Huth (1988) and Huth and Russett (1988). We find that many of the variables involved in the deterrence calculus are nonmonotonically linked to the probability of deterrence success or war. We illustrate the results with case studies of the Soviet-Japanese dispute over Manchukuo (1937-1938) and the Berlin Blockade (1948).
\end{abstract}

W hat factors affect deterrence success or failure? The deterrence literature is one of the most exhaustive in international relations, and the logic of deterrence has been extensively studied within both government and academia by scholars from a variety of disciplines. Scholars have investigated the impact of conventional and nuclear balance of forces, interests at stake, reputation from past crises, crisis bargaining strategies, military alliances, geographic contiguity, degree of uncertainty, international system structure, and domestic politics (e.g., Alexandroff and Rosencrance 1977; Betts 1985, 1987; Fearon 1994a; George and Smoke 1974; Hopf 1994; Huth 1988, 1990; Huth and Russett 1984, 1993; Huth, Gelpi, and Bennett 1993; Langlois 1991; Mearsheimer 1983; Mueller 1989; Paul 1995; Waltz 1981, 1990; Weber 1990). The logic of deterrence is continu- ously put under the microscope of rigorous empirical testing, and subsequently refined. It is no wonder, then, that even the informal rational deterrence literature tends to be transparent in its logic, with much attention paid to the sequencing of moves and to the incentives and expected behavior of other states (see, for example, George and Smoke 1974, 101-103).

Recent research by Signorino (1999) and Signorino and Yilmaz (2003), however, suggests that previous empirical tests of deterrence theories are highly problematic. The heart of the problem is that deterrence is generally considered to be a strategic interaction, but is empirically investigated using nonstrategic statistical models such as logit and probit. ${ }^{1}$ Signorino (1999) demonstrates how failure to incorporate strategic interaction into statistical tests can result in faulty inferences. Signorino and Yilmaz

Curtis S. Signorino is associate professor of political science, University of Rochester, 303 Harkness Hall, Rochester, NY 14627 (curt.signorino@rochester.edu). Ahmer Tarar is assistant professor of political science, Texas A\&M University, 4348 TAMU, College Station, TX 77843-4348 (ahmertarar@polisci.tamu.edu).

Earlier versions of this paper were presented at the 2000 annual meetings of the American Political Science Association, the Midwest Political Science Association, and the Peace Science Society (International). Helpful comments were also received during seminar presentations at Emory University, Harvard University, the University of Wisconsin-Madison, and Yale University, and by participants in the University of Rochester's Watson Center seminar series. In particular, we would like to thank Stuart Bremer, Charles Franklin, Stephen Gent, Arman Grigorian, Paul Huth, Kris Ramsay, Branislav Slantchev, Alan Stam, and Robert Walker for their helpful comments; Kris Ramsay, Dustin Tingley, and Kuzey Yilmaz for their research assistance; and Paul Huth for providing his data. We gratefully acknowledge support from the National Science Foundation (SES-9817947 and SES-0213771 for Signorino, and SES-0518945 for Tarar) and from the Watson Center for Conflict and Cooperation. Derivations, graphs, and additional case studies not included in this article are available from the authors at www.rochester.edu/College/PSC/Signorino.

${ }^{1}$ We use the term "strategic" in the usual game-theoretic sense where there are multiple actors involved, and hence each actor's choices take into account the expected behavior of other actors.

American Journal of Political Science, Vol. 50, No. 3, July 2006, Pp. 586-605 
(2003) show that using logit to analyze data generated by strategic interaction induces the equivalent of omitted variable bias. The upshot of this recent methodological research is that a statistical model needs to be structurally consistent with the theory it is testing. Strategic models imply a particular structural relationship between the regressors and the dependent variable. Typical logit and probit models imply a different structural relationship.

In this study, we present the first unified theory and test of extended immediate deterrence-unified in the sense that we employ our theoretical deterrence model as our statistical model in the empirical analysis. The theoretical model is a straightforward formalization of the extended immediate deterrence logic in Huth (1988) and Huth and Russett $(1984,1988)$, coupled with private information concerning utilities. We construct our deterrence model in such a way that it guarantees positive probabilities over all actions and outcomes, and, therefore, can be used in statistical estimation. That is, our theoretical model is our statistical model.

We analyze this model using data from Huth (1988) and Huth and Russett (1988). Contrary to Huth (1988), our empirical analysis suggests that military alliances, the long-term balance of forces, nuclear weapons, military arms transfers, and foreign trade all affect deterrence success. In contrast to Huth and Russett (1988), we find that the latter three variables, as well as the immediate balance of forces, influence the defender's decision to defend its protege. Additionally, we find that democratic defenders are more likely to fight to defend their proteges, a finding that is consistent with the "audience cost" theory (e.g., Fearon 1994b; Schelling 1960) that leaders who face high domestic audience costs are less likely to back down in public crises. In terms of model fit, the model correctly predicts over $96 \%$ of the potential attacker's actions and over $93 \%$ of the crisis outcomes. Finally, our results indicate that the likelihood of deterrence success and of war are not monotonically related to many of the variables involved in the deterrence calculus. This contradicts a fundamental structural assumption of previous studies using logit, probit, and binary selection models with monotonic link functions.

The paper proceeds as follows. In the next section, we present the theoretical model. Following that, we specify the utilities of the model in terms of regressors. Using data from two previous studies of extended immediate deterrence, we then conduct the empirical analysis. We discuss the factors that influence deterrence success and the decision to go to war and assess model fit. Employing the estimated model, we then examine the effects of the immediate and short-term balance of forces, as well as nuclear capability (where appropriate) in case studies of the Soviet-Japanese dispute over Manchukuo (1937-1938) and the Berlin Blockade (1948). We conclude by suggesting possible avenues for future research.

\section{A Strategic Model of Extended Immediate Deterrence}

A distinct benefit of the relatively transparent rational deterrence logic is that it allows for straightforward translation into a formal model. An excellent example is the literature on extended immediate deterrence (e.g., Huth 1988, 1990; Huth and Russett 1984, 1988). In extended immediate deterrence, a "defender" nation is trying to deter a potential aggressor from attacking one of its allies or "proteges." Henceforth, we will refer to the defender nation simply as the "defender," the potential aggressor as the "attacker," and the defender's ally or protege that is being threatened simply as the "protege." The deterrence situation is considered "extended" in that the defender is attempting to deter an attack on a third nation rather than on itself (i.e., the defender is extending its deterrence umbrella over another nation), and "immediate" in that the attacker has made threats and the defender counterthreats, so that the deterrence attempt takes place in a crisis atmosphere in which the use of force may be imminent (for the distinction between "immediate" and "general" deterrence, see, e.g., Danilovic 2001; Morgan 1983). Of primary interest in this literature is the interaction between the attacker and the defender.

Figure 1 displays this interaction in the form of a simple extensive form game. Here, the (potential) attacker can either attack $(A)$ or not attack $(\bar{A})$ the protege. If the attacker chooses not to attack, the deterrence success results in a status quo (SQ) outcome. If, on the other hand, the attacker chooses to attack, deterrence has clearly failed, and the defender must decide whether to come to the aid of its protege. If the defender chooses to defend $(D)$ against the attacker, war (War) results. If the defender does not defend $(\bar{D})$ its protege, then we regard the defender as having capitulated (Cap).

It is certainly true that more complicated formal deterrence models have been developed than that depicted in Figure 1 (e.g., Fearon 1994a; Kilgour and Zagare 1991; Kugler and Zagare 1987; Powell 1990; Werner 2000; Zagare and Kilgour 1993, 2000). However, we employ this model for a number of reasons. First, we believe that it most closely represents the logic of the extended immediate deterrence literature (Huth 1988, 1990; Huth and Russett 1984, 1988, 1993; Wu 1990). Second, not only has this literature undertaken rigorous empirical testing, 


\section{FIGURE 1 The Deterrence Model with Uncertainty Concerning Utilities}

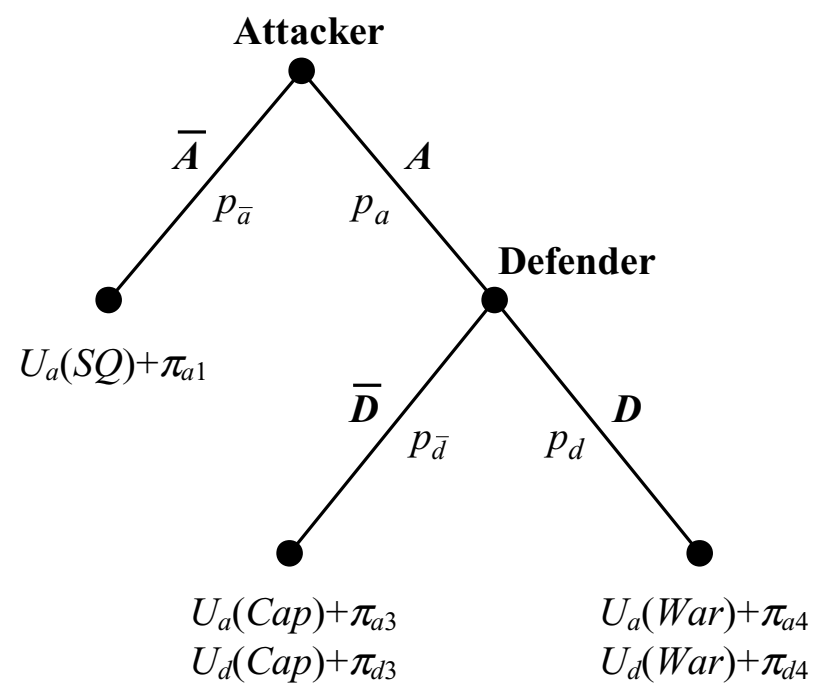

but data exists for testing the model in Figure 1. This is not a trivial issue, given that most data collection in international relations (and political science more generally) has been undertaken without regard to the structure of formal models. Third, given that this study represents the first instance of a unified theory and test of deterrence, we prefer to begin with a simple model rather than a more complex one. Achen and Snidal verbally describe this model, calling it "the simplest version of rational deterrence theory" (1989, 151). Zagare and Kilgour (2000, Chapter 3) formally analyze complete and incomplete information versions of this model. Therefore, this seems to be a good place to start.

However, there is an important issue, namely that this game tree does not model the entire deterrence interaction. In particular, this model does not capture the attacker's decision of whether or not to issue a threat in the first place and the defender's decision of whether or not to respond to the threat, if made (this is the "general deterrence" phase of the interaction). Ideally, we would model and empirically estimate the entire interaction. However, because of data limitations that are discussed in more detail in the conclusion, we cannot currently do this. Because we are not modeling the entire interaction, it is possible that selection effects are influencing our results. For example, Huth and Russett (1984) found the anomalous result that when the defender and protege have a military alliance, deterrence is actually more likely to fail, which is rather counterintuitive. Huth and Russett (1984) provided a brief, and Fearon (1994a) a more detailed, "selection effect" explanation for this, namely that when there is a defender-protege military alliance, the attacker knows that the defender is likely to defend, and hence the attacker will only initiate a crisis in the first place if it is quite willing to go to war with the defender. Therefore, in the immediate deterrence subgame, a defender-protege military alliance is actually associated with a greater attacker likelihood of attacking. In our results, a similar dynamic may be in effect. Indeed, we also have a couple of anomalous findings, including the same one with military alliances, which may be due to selection effects (we discuss these more below). However, most of our findings, although many are new, are quite intuitive (similarly, Huth and Russett 1984 also had only one anomalous finding — selection effects may have mitigated the magnitudes of the estimated coefficients, but only "reversed" the sign in a single case). Future research that empirically estimates the entire deterrence interaction will provide greater information about whether or not selection effects are influencing our results. We return to this issue in the conclusion.

\section{Uncertainty Concerning Utilities}

It is unlikely that the participants of a deterrence crisis (or almost any situation, for that matter) perfectly observe each other's utilities. It is also unlikely that the analyst, in conducting the empirical analysis, can perfectly specify the actors' utilities. Fortunately, relaxing this assumption not only provides a model that is more satisfying theoretically, but also one that can be used as the basis of our statistical estimation.

Consider the specification in Figure 1. Here we assume that the true utility for an outcome can be represented as consisting of an observable component and an unobservable (or private) component. For example, let the defender's utility for war be represented as

$$
U_{d}^{*}(\text { War })=U_{d}(\text { War })+\pi_{d 4}
$$

where $U_{d}^{*}($ War $)$ is the defender's true utility for war, $U_{d}$ (War) is the component of the true utility that the attacker and the analyst can observe, and $\pi_{d 4}$ is the component that is private information to the defender. From the attacker's and analyst's perspective, we assume that $\pi_{d 4}$ is a random variable. We assume that the attacker and the analyst know only the distribution of $\pi_{d 4}$. We also assume that the analyst does not perfectly observe the attacker's utilities.

If, as depicted in Figure 1, we make this assumption concerning each of the players' utilities, we can derive equilibrium choice probabilities for each of the actions and outcomes in the game (see Signorino 2003 for details 
on deriving the choice probabilities of various "strategic probit" models). We assume that the payoff perturbations (i.e., the $\pi_{i j}$ 's) are independently and identically distributed normally with mean 0 and variance $\sigma^{2}$, i.e., $N\left(0, \sigma^{2}\right)$. Let $p_{d}$ denote the probability that the defender defends its protege and $p_{a}$ the probability that the attacker attacks the protege. Conversely, let $p_{\bar{d}}$ and $p_{\bar{a}}$ denote the probabilities that the defender does not defend and that the attacker does not attack, respectively. Assuming that the actors maximize their true (expected) utility at their decision nodes, the strategic probit choice probabilities for the deterrence model in Figure 1 are easily derived as

$$
\begin{aligned}
& p_{d}=\Phi\left[\frac{U_{d}(\text { War })-U_{d}(\text { Cap })}{\sqrt{2 \sigma^{2}}}\right] \\
& p_{a}=\Phi\left[\frac{p_{d} U_{a}(\text { War })+p_{\bar{d}} U_{a}(\text { Cap })-U_{a}(S Q)}{\sqrt{\sigma^{2}\left(p_{d}^{2}+p_{\bar{d}}^{2}+1\right)}}\right]
\end{aligned}
$$

where $\Phi(\cdot)$ is the standard Normal cumulative distribution function, and where $p_{\bar{d}}=1-p_{d}$ and $p_{\bar{a}}=1-p_{a}{ }^{2}$

Notice that the equilibrium choice probabilities reflect the extended immediate deterrence logic of the extensive form game and the uncertainty of the players concerning each other's payoffs. The numerators of equations (1) and (2) express the difference in observed expected utility for the options associated with each decision node. For example, the probability $p_{d}$ (from the perspective of the attacker and analyst) that the defender aids its protege is based on the difference in the defender's observed utility for war and its observed utility for capitulation: the higher the defender's observed utility for war relative to capitulation, the higher the probability that the defender will defend its protege.

Similarly, the numerator of equation (2) is simply the difference between the attacker's observed expected utility for attacking and its observed utility for not attacking. The attacker's observed expected utility for attacking, $E U_{a}(A)$, is a lottery over the capitulation and war outcomes, based on the attacker's belief $p_{d}$ about whether the defender will defend its protege: $E U_{a}(A)=$ $p_{d} U_{a}($ War $)+p_{\bar{d}} U_{a}($ Cap $)$. The higher the attacker's observed expected utility for attacking relative to its observed utility for the status quo, the higher the probability (from the analyst's perspective) that the attacker will attack.

The denominator of each probability equation is a variance term, reflecting the amount of uncertainty regarding the unobserved component of the true utilities.

\footnotetext{
${ }^{2}$ The derivation of the choice probabilities is straightforward. The derivations are also available in the supplement to this paper, which can be downloaded from the aforementioned website.
}

A large $\sigma^{2}$ relative to the observable components reflects greater uncertainty on the part of the actors and the analyst, resulting in strategic choice probabilities closer to a coin toss over the options at each decision node. When the players and the analyst have more accurate information about the true utilities-i.e., when $\sigma^{2}$ is small-the choice probabilities approach 0 and 1 , and the deterrence model in Figure 1 approaches that of a game of perfect and complete information. Note that when $\sigma^{2}=0$, the game is exactly one of perfect and complete information, and our assumption that states maximize their utility at each decision node implies subgame perfection.

It should also be noted that equations (1) and (2) do not represent mixed strategies. Rather, they are the beliefs of the attacker and the analyst, based on their assumptions of utility maximizing behavior, uncertainty concerning the $\pi_{i j}$ 's, and the structure of the game. $p_{d}$ is the belief of both the attacker and the analyst about whether the defender will fight. $p_{a}$ represents the analyst's belief about whether the attacker will attack, given the attacker's (and analyst's) belief about whether the defender will defend. Except in a few knife-edge situations, the underlying behavioral model assumes that the attacker and the defender play pure strategies from their perspective. ${ }^{3}$ The twist (relative to conventional game theory) is that the empirical analyst is assumed to know only the distribution of the $\pi_{i j}$ 's. Therefore, the analyst can only make probabilistic statements about the equilibrium choices. ${ }^{4}$

The equilibrium outcome probabilities follow directly from the action probabilities. Let $p_{s q}, p_{c a p}$, and $p_{w a r}$ be the probabilities of the status quo, capitulation, and war outcomes, respectively. Because of the independence assumption, the probability of any given outcome is simply the product of the action probabilities along its path. Hence,

$$
\begin{gathered}
p_{s q}=p_{\bar{a}} \\
p_{c a p}=p_{a} p_{\bar{d}} \\
p_{w a r}=p_{a} p_{d}
\end{gathered}
$$

We now have an equilibrium-based deterrence model that is also a statistical (i.e., probabilistic) model. As long as there is some uncertainty concerning the true utilities (on the part of the states and the analyst), we are guaranteed positive probabilities over all actions and all outcomes

\footnotetext{
${ }^{3}$ The defender chooses $D$ if and only if $U_{d}^{*}($ War $)>U_{d}^{*}($ Cap $)$. The attacker chooses $A$ if and only if $p_{d} U_{a}^{*}($ War $)+p_{\bar{d}} U_{a}^{*}($ Cap $)>$ $U_{a}^{*}(S Q)$.
}

${ }^{4}$ This is essentially a two-player extensive-form game of two-sided incomplete information, but in which the analyst is also imperfectly informed about the actors' utilities. 
in the model, and we can therefore use this theoretical model directly in our statistical estimation. In doing so, the deterrence theory and its test are unified.

\section{Empirical Analysis}

The typical empirical analysis, not only in the deterrence literature but in much of the international relations literature, begins with a list of hypotheses drawn from extant theory. In these cases, the hypotheses to be tested almost invariably involve unconditionally monotonic relationships between the dependent variable and the regressors. In the current context, an example of such a hypothesis would be:

\section{$H$ : The likelihood of war decreases as the balance of forces increasingly favors the defender.}

As Signorino and Yilmaz (2003) show, however, even the simplest strategic model often implies nonmonotonicor at least only conditionally monotonic-relationships between the dependent variable and the regressors. ${ }^{5}$ That our strategic theories often imply nonmonotonic or only conditionally monotonic relationships suggests that typical hypothesis statements are problematic, especially when there is no clear link from the hypothesis to a wellspecified model. ${ }^{6}$ Because of that and because we have a statistical model that is also our theoretical model, we take a slightly different approach here.

In conducting hypothesis tests, we are usually interested in assessing whether some explanatory variable has an effect on the the phenomenon of interest. In the present context, we might hypothesize that the balance of military forces or the defender's possession of nuclear weapons affect the attacker's decision to attack. Alternatively, we might hypothesize that other variables, such as past crisis behavior or current bargaining behavior, contribute to

${ }^{5}$ The relationship in the above hypothesis is monotonic because it implies that as we increase the value of the explanatory variable, the dependent variable always decreases, holding all other variables constant. The hypothesis is also unconditionally monotonic because it is assumed that the monotonicity and its direction hold for every possible set of values at which the other variables could be held constant. Conditional monotonicity implies monotonicity for every set of values at which the other variables are held, but allows the direction of that monotonic relationship to differ, depending on the values at which the other variables are held.

${ }^{6}$ We are not suggesting that hypothesis testing as a method of inference is problematic, only the (typical) listing of unconditionally monotonic hypotheses with no clear (i.e., derivable) link to a strategic model.

\section{FIGURE 2 Specification of Utilities in Terms of Regressors}

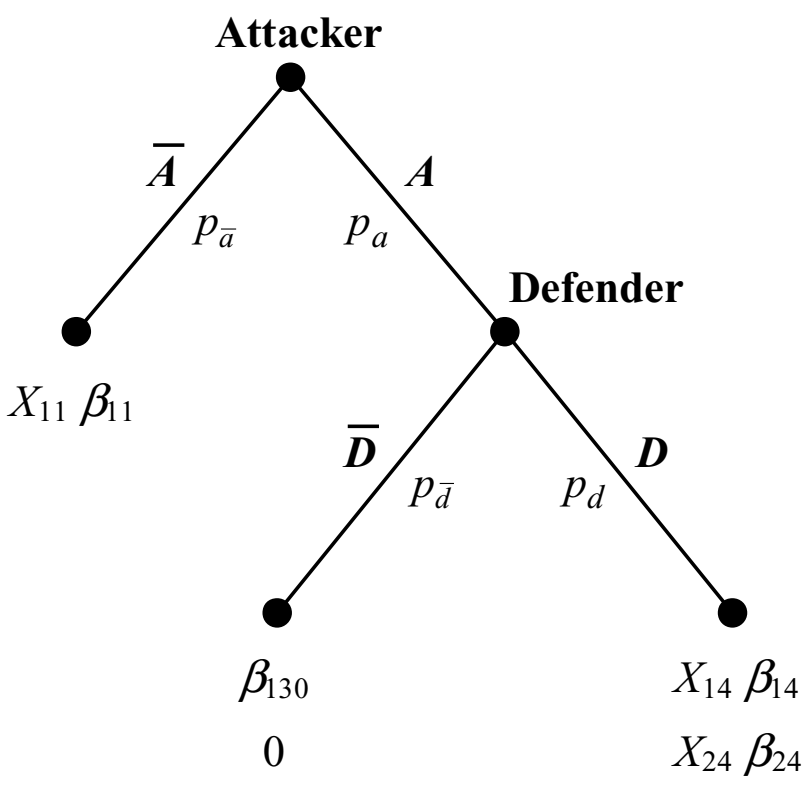

deterrence success (Huth 1988). Deciding which variables enter into each of the utilities in the game and how to estimate the parameters associated with those variables are not trivial matters. Ideally, theory should be the guide, not only for the structure of the interaction, but also for the specification of the utilities. In a perfect world, we would have variables representing the "primitives" of state preferences. Indeed, the functional form of the utility equations should also be theoretically justified. With little else to go on, our approach is to specify the set of utilities for a player as simply as possible and with an eye towards differences in utilities, since it is the size of the utilities relative to each other that determine the equilibrium choice probabilities.

Figure 2 shows the general specification of the utilities employed in the subsequent data analysis. Here, the attacker's observed utility for the status quo $U_{a}(S Q)$ is a linear function $X_{11} \beta_{11}$ of explanatory variables, where $\beta_{11}$ is a vector of coefficients to be estimated, its observed utility for the defender's capitulation $U_{a}(C a p)$ is estimated as a constant $\beta_{130}$, and its observed utility for war $U_{a}($ War $)$ is a linear function $X_{14} \beta_{14}$ of explanatory variables. In this manner, we are able to differentiate the attacker's utility for war from its utility for capitulation, and its utility for attacking from its utility for not attacking (i.e., the status quo). The defender's utility for capitulation $U_{d}(C a p)$ is normalized to zero and we treat its utility for 
war $U_{d}($ War $)$ as a linear function $X_{24} \beta_{24}$ of explanatory variables. ${ }^{7}$

The estimation method we employ is detailed in Signorino (2003). The equilibrium outcome probabilities in equations (3-5) are used as the basis of maximum-likelihood estimation. Let $y_{s q, i}=1$ if the crisis in observation $i$ resulted in a status quo outcome, and zero otherwise. Let $y_{c a p, i}=1$ if the crisis resulted in capitulation by the defender, and zero otherwise. Let $y_{\text {war }, i}=1$ if the crisis resulted in war between the attacker and the defender, and zero otherwise. Then, the log-likelihood to be maximized (with respect to the $\beta$ 's) is

$$
\begin{aligned}
\ln \mathrm{L}= & \sum_{i=1}^{N}\left[y_{s q, i} \ln p_{s q, i}+y_{c a p, i} \ln p_{c a p, i}\right. \\
& \left.+y_{\text {war }, i} \ln p_{\text {war }, i}\right]
\end{aligned}
$$

One generally cannot estimate the effects parameters (i.e., the $\beta$ 's) and the variance parameter $\sigma$ individually. As with most other discrete choice models, they are not all individually identified. As in standard (i.e., nonstrategic) probit estimation, we normalize $\sigma^{2}$ to one. Parameter estimates are therefore actually estimates of the $\beta$ 's and $\sigma$ to scale.

\section{Variables and Data}

The bulk of the data used here comes from the previous studies of Huth (1988) and Huth and Russett (1988), which examine 58 extended immediate deterrence crises from 1885 to 1983 . The dependent variable in our study is which of the outcomes $\{S Q$, Cap, War $\}$ occurred in each of the 58 crises. In the context of our model, the dependent variable examined in Huth (1988) is whether the attacker attacked or not, $A$ versus $\bar{A}$, respectively. Huth and Russett (1988) followed Huth (1988) with an analysis of the defender's actions (defend or not defend) in those 24 cases in which the attacker attacked. In the context of our model, Huth and Russett (1988) provide data on whether the defender defended or not, $D$ versus $\bar{D}$, given that the attacker used force against the protege. The sequence of actions coded in these two studies match the actions in our deterrence model, and, therefore, provide all the information we need to code the outcome for each observation.

Most of our explanatory variables are drawn from Huth (1988). Rather that repeat their operationalizations, we refer the reader to Huth (1988) for the complete de-

\footnotetext{
${ }^{7}$ Note that the defender's utility for the status quo does not affect the equilibrium choice probabilities $p_{d}$ and $p_{a}$, which is why we do not provide a specification for it.
}

tails. In general, they can be grouped under the following headings:

Balance of Forces: Whether the defender possessed nuclear weapons (NUCLEAR $=1$ if the defender possessed nuclear weapons, 0 otherwise). The immediate balance of forces $(I B F)$ as a ratio of the defenderprotege's forces to the attacker's-i.e., $I B F>1$ implies a stronger defender-protege, and $I B F<1$ implies a stronger attacker. The short-term balance of forces $(S B F)$. The long-term balance of forces $(L B F) .{ }^{8}$

Defender's Interests at Stake: Whether the defender and protege had a military alliance $(M I L A L L=1$ if yes, 0 otherwise). The percentage of the protege's arms imports that come from the defender (MILARM), scaled from 1-10. The protege's share of the defender's total merchandise imports and exports (FORTRADE), scaled from $0-10$.

Defender's Reputation from its Last Extended Immediate Deterrence Crisis: Whether the defender successfully deterred an opponent in its last crisis (PAST$D E T=1$ if yes, 0 otherwise). Whether the defender came to its protege's aid in its last crisis, if the opponent was not deterred (ARMED). Whether the defender capitulated in its last crisis, if the opponent was not deterred (CAPITU). All three of these variables equal zero when the defender has never been in an extended immediate deterrence crisis before.

Defender's Reputation from its Last Crisis with the Current Attacker: Whether the defender adopted a bullying strategy or forced the attacker to make critical concessions in order to avoid armed conflict, or both (PUTDOWN). Whether the defender and attacker avoided a military confrontation, but failed to resolve the underlying issues of the dispute (STALEMATE). Whether the defender retreated under diplomatic

${ }^{8} I B F$ is measured as the ratio of the defender-protege ground troops to the potential attacker's ground troops, including only those troops that are at forward positions and that can be deployed to the scene of the battle immediately. SBF includes each side's standing ground and air forces and first class of trained reserves; it measures each side's ability to reinforce the troops that are deployed at or near the scene of the battle, as measured by $I B F$. Huth defines $L B F$ as "the capacity of the defender and protege and the potential attacker to build up their existing armed forces (army, air, and naval manpower) and to maintain an increased level of fighting strength by mobilizing the economy and civilian population for war. . . Each state's existing military capabilities (percentage share of world military personnel and military expenditures) were multiplied by the sum of that state's industrial and demographic resources (percentage share of world steel production, industrial fuel consumption, urban, and total population). The ratio of defender's and protege's capabilities to potential attacker's capabilities was then calculated" (1988, 61-62). 
and/or military pressure from the attacker in order to avoid armed conflict (DIPLO). All three of these variables equal zero if the attacker and defender have never been in a crisis before.

Defender's Bargaining Behavior in the Current Crisis: Whether the defender has adopted a "firm-butflexible," rather than bullying or conciliatory, strategy in diplomatic negotiations until now (FIRMFLEX). Whether the defender has responded proportionally to, rather than overmatched or undermatched, the military preparations of the attacker until now (TFT).

Others: Whether the attacker and defender are territorially contiguous (CONTIGAD) ${ }^{9}$ Whether the attacker and protege are contiguous (CONTIGAP). Whether the defender and protege are contiguous (CONTIGDP). Whether or not the defender was a democracy (DEMDEF). ${ }^{10}$ Whether or not the attacker was a democracy (DEMATT). We also include a variable (SYEAR) that controls for trends over time. It simply indexes the date of the crisis in the data set. SYEAR is coded as the calendar year of the crisis minus 1885, which is the earliest calendar year in the data. ${ }^{11}$

\section{Strategic Probit Analysis}

Based on the strategic deterrence model and using the preceding regressors, a total of four strategic probit regressions were conducted, representing four different theoretical perspectives-e.g., a "realist" balance of forces model, a model based on the defender's interests at stake, a reputation and bargaining model, and a final model that combined all three.

Perhaps not surprisingly, the combined model far outperformed the other three, and we report in Table 1 the maximum-likelihood estimates for only that model. The four columns in Table 1 are not four different models, but estimates of the four utility functions shown in Figure 2. Column 1 shows the estimates $\left(\hat{\beta}_{24}\right)$ for the defender's utility for war-i.e., they are the $\hat{\beta}_{24}$ from $U_{d}($ War $)=X_{24} \beta_{24}$.

\footnotetext{
${ }^{9}$ We use strict land contiguity.

${ }^{10}$ To determine this, we use the POLITY III data set, which contains information on the regime characteristics for all of the states in the international system for the time period 1800-1994 (Jaggers and Gurr 1996). We use the commonly used method (e.g., Rousseau et al. 1996; Schultz 1999) of subtracting the 11-point autocracy score from the 11-point democracy score, to create a measure ranging from -10 (entirely autocratic) to 10 (entirely democratic). If the difference is at least five, the state is coded as a democracy (the results are identical if we use a threshold of six or seven instead).

${ }^{11}$ Using the raw calendar year causes numerical problems in the estimation, because the magnitude of the calendar year is much larger than that of the other explanatory variables.
}

Column 2 shows the estimates $\left(\hat{\beta}_{14}\right)$ for the attacker's utility for war. Column 3 displays the estimates $\left(\hat{\beta}_{11}\right)$ for the attacker's utility for the status quo. Finally, column 4 shows the estimate $\left(\hat{\beta}_{130}\right)$ for the attacker's utility for the defender's capitulation. Standard errors are shown below the estimates. Estimates with one asterisk are statistically significant at $p<.08$ (two-tailed), and estimates with two asterisks are significant at $p<.02$. Finally, the mean loglikelihood, the percentage of outcomes (war, status quo, or capitulation) correctly predicted (actually, postdicted), and the percentage of the attacker's actions (attack or not attack) correctly predicted are displayed at the bottom to provide a sense of how well the model fares.

To briefly summarize the results, contrary to Huth (1988), the results suggest that military alliances, the longterm balance of forces, nuclear weapons, military arms transfers, and foreign trade all affect deterrence success. In contrast to Huth and Russett (1988), the results suggest that the latter three variables, as well as the immediate balance of forces, influence the defender's decision to defend its protege. We find that democratic defenders are more likely to fight to defend their proteges, a finding that is consistent with the "audience cost" theory (e.g., Fearon 1994b; Schelling 1960) that leaders who face high domestic audience costs are less likely to back down in public crises. The model correctly predicts over $96 \%$ of the attacker's actions and over $93 \%$ of the outcomes. We now discuss the results in more detail. ${ }^{12}$

\footnotetext{
${ }^{12}$ The choice of which regressors to place in which utility equations is not an easy one. The first issue is that the placement of the regressors has to be chosen so as to ensure that the model is statistically identified. Lewis and Schultz (2003) discuss the identification issue in the context of statistical strategic models in more detail. The main issue in this regard is that the same regressor cannot go into all of an actor's utilities (which is not substantively necessary anyway, since it is the differences in the utilities that matter, not the absolute values). One option that we could have chosen is to normalize the attacker's utility for the SQ outcome to be 0 , the Cap outcome to be 1 , and then throw all of the relevant regressors into the attacker's utility for the War outcome (this is essentially what we have done for the defender's utilities, in which case it is more justified, since there are only two utilities that affect the defender's choices, and hence normalizing one of them to zero does not pose any substantive problems). The problems with this approach would be that, (1) it imposes the restriction that the attacker must always prefer the Cap outcome to the $S Q$ outcome (which may be substantively justified, but is a restriction nonetheless) and (2) imposes the restriction that for all attackers in the data set, the intensity of the preference for the Cap outcome over the SQ outcome must be the same. By adding regressors to the attacker's utility for the $S Q$ outcome, we allow the intensity of the preference for the Cap outcome over the SQ outcome to differ for different attackers, in a way that is determined by the data. Moreover, Huth (1988) specifically theorizes that some of the regressors in his data set, such as tit-for-tat military preparations by the defender, explicitly affect the attacker's utility for the $S Q$ (this is discussed in more detail below), and hence it would be substantively inappropriate to insert them in the attacker's utility for war instead. Such variables are inserted in the attacker's utility
} 
TABLE 1 Strategic Probit Regression. The Table Displays the Results of the Strategic Probit Regression Based on the Model in Figure 2. The Four Columns Report the Maximum Likelihood Estimates of the Coefficients Associated with the Variables Entering into the Defender's Utility for War $\left(\hat{\boldsymbol{\beta}}_{24}\right)$, the Attacker's Utility for War $\left(\hat{\boldsymbol{\beta}}_{14}\right)$, the Attacker's Utility for the Status Quo $\left(\hat{\boldsymbol{\beta}}_{11}\right)$, And the Attacker's Utility for the Defender's Capitulation $\left(\hat{\boldsymbol{\beta}}_{130}\right)$, Respectively

\begin{tabular}{|c|c|c|c|c|}
\hline & $U_{d}($ War $)$ & $U_{a}($ War $)$ & $U_{a}(\mathrm{SQ})$ & $U_{a}($ Cap $)$ \\
\hline \multirow[t]{2}{*}{ Constant } & $-10.98^{*}$ & & $-5.04^{*}$ & 13.46 \\
\hline & 5.93 & & 2.39 & 12.74 \\
\hline \multirow[t]{2}{*}{ Nuclear } & $6.65^{* *}$ & $-9.18^{*}$ & & \\
\hline & 2.64 & 5.29 & & \\
\hline \multirow[t]{2}{*}{ Immediate Balance } & $5.49^{*}$ & $-12.57^{* *}$ & & \\
\hline & 2.92 & 5.29 & & \\
\hline \multirow[t]{2}{*}{ Short-term Balance } & $4.17^{*}$ & $-6.23^{*}$ & & \\
\hline & 2.38 & 3.28 & & \\
\hline \multirow[t]{2}{*}{ Long-term Balance } & & $3.37^{*}$ & & \\
\hline & & 1.57 & & \\
\hline \multirow[t]{2}{*}{ Military Alliance } & $13.46^{*}$ & $12.68^{* *}$ & & \\
\hline & 7.68 & 5.26 & & \\
\hline \multirow[t]{2}{*}{ Arms Transfers } & $-1.76^{*}$ & $-.86^{*}$ & & \\
\hline & .87 & .49 & & \\
\hline \multirow[t]{2}{*}{ Foreign Trade } & $4.86^{*}$ & & & \\
\hline & 2.58 & & & \\
\hline \multirow[t]{2}{*}{ Tit-for-Tat } & & & $17.33^{* *}$ & \\
\hline & & & 7.26 & \\
\hline \multirow[t]{2}{*}{ FirmFlex } & & & $6.61^{*}$ & \\
\hline & & & 3.27 & \\
\hline \multirow[t]{2}{*}{ Stalemate } & $8.43^{*}$ & & & \\
\hline & 4.24 & & & \\
\hline \multirow[t]{2}{*}{ Democratic Defender } & $5.94^{*}$ & & & \\
\hline & 2.89 & & & \\
\hline \multirow[t]{2}{*}{ Democratic Attacker } & & & $15.82^{*}$ & \\
\hline & & & 8.64 & \\
\hline \multirow[t]{2}{*}{ Year } & & & $-.35^{*}$ & \\
\hline & & & .18 & \\
\hline Mean $\ln \mathrm{L}$ & -.214 & & & \\
\hline PCP Outcomes & 93.1 & & & \\
\hline PCP Deter & 96.5 & & & \\
\hline
\end{tabular}

Standard errors are shown below parameter estimates. $\mathrm{N}=58 .{ }^{* *} \mathrm{p}<.02 .{ }^{*} \mathrm{p}<.08$. (two-tailed).

\section{The Defender's Utility for War}

As seen in the first column of Table 1, the results suggest that the defender's utility for war is higher, and hence the defender is more likely to fight to defend

for the $S Q$, and the remainder are inserted in the attacker's utility for war. The statistically insignificant variables are dropped from the final analysis, because we are already estimating a large number of parameters from a relatively small data set. the protege, when (1) the defender possesses nuclear weapons, (2) the immediate and short-term balance of forces increasingly favor the defender-protege, (3) there is a military alliance between the defender and protege, (4) the defender is increasingly reliant on the protege for its foreign trade, and (5) there was a past crisis between the defender and attacker that ended without the use of force but without the underlying issues of the dispute being resolved. All of these results are quite 
intuitive. Of particular note is that in contrast to Huth and Russett (1988), we find that nuclear-armed defenders are more likely to defend their proteges than are nonnuclear defenders.

Interestingly, we also find that democratic states are more likely to go to war to defend their proteges than are nondemocratic states (Huth (1988) and Huth and Russett (1988) did not investigate the effect of regime type). At least two different explanations can be given for this finding. A norms-based explanation would be that democracies are simply more loyal to proteges than are authoritarian regimes. An alternative explanation is based on the "audience cost" theory of costly signaling in international crises (e.g., Fearon 1994b; Schelling 1960). We can hypothesize that democratic leaders who publicly escalate a crisis involving the defense of a protege will generally face larger audience costs (e.g., electoral costs) if they back down than would an authoritarian leader. The data analyzed here consists of cases of immediate deterrence, in which threats and counterthreats have already been made, and hence potential audience costs have been generated. If democratic leaders tend to face greater domestic audience costs on average than their authoritarian counterparts for backing down in public crises, then they should be more likely to fight to defend their proteges after potential audience costs have been raised, other things equal. Indeed, this is what we find, and the results thus provide some empirical support for the audience cost hypothesis.

Somewhat surprisingly, we find that the more heavily the protege relies on the defender for its arms imports, the less likely the defender is to go to war to protect the protege. This suggests that in many cases, a defender sends a lot of arms to its protege precisely when it does not expect to defend the protege if the protege is attacked. In a similar vein, Fearon (1994a, 260) notes a negative simple bivariate correlation between arms transfers and the defender's decision to defend and suggests that the defender may use high arms transfers as a low-cost substitute for a more serious commitment to defend the protege, precisely when it does not actually plan to defend. An implication of this is that neither a potential aggressor nor a protege should take high levels of defender-protege arms transfers as a credible indicator that the defender will fight to defend the protege. ${ }^{13}$

\footnotetext{
${ }^{13}$ This gets to another important issue, namely that the results that we find are better interpreted as statistical associations rather than direct causal effects. For example, it is unlikely that a high level of defender-protege arms transfers directly causes a decrease in the defender's utility for war. Rather, because of the reasons discussed above, high levels of defender-protege arms transfers are associated with a lower probability of the defender defending. Because we
}

\section{The Attacker's Utilities}

Now consider the attacker's utility for war. As seen in the second column of Table 1, our results suggest that potential attackers value war less when (1) the defender has a nuclear capability, (2) the immediate and short-term balance of forces favor the defender-protege, and (3) arms transfers between the defender and protege are high. On that last note, although a defender may use arms transfers as a surrogate for defending the protege, everything else equal, the attacker would prefer that the protege be less well armed. All of these results are quite intuitive.

Surprisingly, however, we find that a higher defenderprotege advantage in the long-term balance of forces is actually associated with an increase in the attacker's utility for war. Recall that the long-term balance of forces $(L B F)$ consists of the standing armed forces as well as demographic and industrial factors. It reflects each side's ability to mobilize for and sustain a protracted armed conflictor, alternatively, resources that may be converted to military ends at some point in the future. Therefore, one explanation for this anomalous finding is that, controlling for the existing military forces (i.e., the short-term balance of forces), higher values of $L B F$ indicate that the defender-protege has a lot of untapped military potential and may therefore be a more formidable foe in the future, and that it may be better to fight the defender-protege now rather than wait until they have converted their untapped military potential into actual military might. ${ }^{14}$ For instance, in the years leading up to World War I, many German officials were concerned that Russia's potential was such that she would soon be much more powerful, and if war was inevitable anyway, it was better to fight her now rather than later (e.g., Rich 1992, 435-36; Taylor $1954,511,515,522,527-28)$.

Another surprising result is that a defender-protege military alliance is actually associated with an increase in the attacker's utility for war. This may be due to a selection effect. Recall that a defender-protege alliance makes it more likely that the defender will fight to defend the protege. If a forward-looking potential attacker can anticipate this, it will only initiate a crisis when there is a defenderprotege alliance if it is in fact quite ready to go to war with the defender (this is similar to Fearon's (1994a) selection

do not model the entire deterrence interaction, certain variables may affect the probability of different outcomes or actions through prior stages in the deterrence interaction, rather than directly in the immediate deterrence phase. Future research that models the entire interaction will allow us to disaggregate these effects in a more systematic way.

${ }^{14}$ Our thanks to Robert Walker for suggesting this. 
effect argument). ${ }^{15}$ Thus, in the sample of immediate deterrence crises, a defender-protege military alliance appears to be highly correlated with the attacker's utility for going to war with the defender. Indeed, the anomalous finding regarding the long-term balance of forces may also be due to a selection effect like this.

Now consider the attacker's utility for the status quo (the third column of Table 1). The variables included here reflect the extent to which the potential attacker values the status quo relative to attacking the protege and possibly entering into a war with the defender. The variables do not differentiate between capitulation and war-only between attacking and not attacking.

As seen in the third column of Table 1, our results suggest that tit-for-tat military preparations by the defender in the current crisis are associated with an increase in the attacker's utility for the status quo, as is firm-but-flexible diplomatic bargaining by the defender. These results are consistent with Huth (1988), who argues that tit-for-tat military preparations and firm-but-flexible diplomatic bargaining indicate that the defender is resolved to defend its protege, but does not provoke the attacker by putting its reputation and credibility on the line, as a more aggressive/bullying bargaining strategy by the defender might. In other words, tit-for-tat and firm-but-flexible behavior allows the attacker to back down without losing face. ${ }^{16}$

The results also indicate that democratic states (as potential attackers) prefer the status quo more than authoritarian states in the same situation. This finding would seem to contradict the audience-cost hypothesis that democratic states are less likely to back down in public crises. An alternative hypothesis is that democratic audiences differentiate between their state attacking versus defending. Once a democracy or its protege is attacked, audience costs are likely to be very large. However, democratic citizens generally do not like being perceived as aggressors. In some sense that could create audience costs in the opposite direction-against attacking—resulting in an observed preference by democracies for the status quo.

Finally, note that the effect of the "year" variable, which represents otherwise unexplained trends over time, is negative-i.e., as time progresses in the data, the po-

\footnotetext{
${ }^{15}$ An alternative selection effect argument would be that when there is a defender-protege alliance, the attacker only initiates a crisis if it believes that the alliance will not be honored (e.g., Smith 1996). However, we find that an alliance actually increases the likelihood that the defender will defend its protege, and so unless the attacker is systematically miscalculating, the other selection effect seems more reasonable.

${ }^{16}$ It is for this reason that we place these variables in the attacker's utility for the status quo, rather than its utility for war.
}

tential attacker is more likely to attack. It could be the case that potential attackers have increasingly entered into crises with the intention of attacking. However, without further historical investigation and a more complicated dynamic model, it is difficult to explain why this would be the case.

\section{The Probability of Deterrence Success and of War}

As in other discrete choice models (such as multinomial or ordered probit), interpreting the relationship between the dependent and independent variables simply by examining the regression results is difficult. A better means for assessing those relationships is by determining how estimated probabilities of outcomes change as the values of the explanatory variables change. One advantage of our strategic probit analysis is that we can assess the impact of the explanatory variables not only on the probability of deterrence success (to which Huth (1988) is limited), but also on any of the other actions or outcomes of the model. In addition to examining the effects of the explanatory variables on the probability of deterrence success $\left(p_{s q}\right)$, we will also analyze their impact on the probability of war between the attacker and defender $\left(p_{\text {war }}\right)$. For both of these, we use the equilibrium probabilities in equations (1-5) and the estimates reported in Table 1.

It is important to note that, in the deterrence model, relevant variables can affect the attacker's behavior in two ways: directly through its utilities for the various outcomes and indirectly through its belief $p_{d}$ about whether the defender will defend. The attacker attacks if and only if its true expected utility for attacking is greater than its true utility for the status quo, i.e., if and only if $p_{d} U_{a}^{*}(W a r)+p_{\bar{d}} U_{a}^{*}(C a p)>U_{a}^{*}(S Q)$. Recall that $p_{d}$ is a function of the explanatory variables in the defender's utility for war, $X_{24}$ (equation 1). Hence, those variables affect not only the defender's decision to defend, but also the attacker's decision to attack, albeit indirectly, through $p_{d}$. In other words, variables that enter into the defender's utility for war but not the attacker's utilities, such as the regime type of the defender, still affect the attacker's decision to attack or not, because they affect its estimation of whether or not the defender will defend (they thus affect the attacker's expected utility for attacking). Variables that enter into both the attacker's and the defender's utilities, such as the immediate balance of forces, have a direct as well as an indirect effect on the attacker's decision to attack or not.

It is typical in analyses of fitted values or first differences to hold "all other variables" (i.e., other than 


\section{TABle 2 Minimal, Low, Moderate, and Mean Values of Explanatory Variables}

\begin{tabular}{lcccl}
\hline & Minimal & Low & Moderate & Mean* \\
\hline Nuclear & 0 & 0 & 0 & 0 \\
Immediate Balance & .5 & .75 & 1.25 & 1.21 \\
Short-term Balance & .5 & .75 & 1.25 & 1.19 \\
Long-term Balance & .5 & .75 & 1.25 & 1.97 \\
Military Alliance & 0 & 0 & 0 & 0 \\
Arms Transfers & 1 & 2 & 6 & 5.10 \\
Foreign Trade & 1 & 2 & 6 & 1.74 \\
Tit-for-Tat & 0 & 0 & 0 & 1 \\
Firm but Flexible & 0 & 0 & 0 & 0 \\
Stalemate & 0 & 0 & 0 & 0 \\
Democratic Defender & 0 & 0 & 0 & 1 \\
Democratic Attacker & 0 & 0 & 0 & 0 \\
Year & 52 & 52 & 52 & 52 \\
\hline
\end{tabular}

*The median is shown for the binary variables and for Year.

the one being varied) constant at some values, usually their means. However, seven of the explanatory variables in Table 1 are binary, and their means are values we would never observe in the data. Moreover, although it is not commonly done, it might be substantively interesting to examine the impact of the explanatory variables in situations other than that represented by their means. Therefore, to provide a more nuanced picture of the explanatory variables' effects on deterrence success and on war, we calculate estimated probabilities holding all other variables constant at what we call their "minimal," "low," and "moderate" values. These values are displayed in Table 2. In addition, Table 2 also displays the mean values of the continuous explanatory variables and the median values of the binary ones.

Of course, no crisis in the data perfectly matches the combination of values expressed by any of the three cases. They are simply references or ideal types for the analysis (later on, we examine predicted probabilities for actual cases in the data). We have chosen relatively low values for the variables because of the generally cumulative nature of deterrents. If a defending state possesses nuclear weapons and has a large advantage in both the immediate and short-term balance of forces, it is highly unlikely that another state will attack. Not surprisingly, in our analysis when these (or other) variables are set to relatively large values, often a single variable will have no observable effect on relevant probabilities (e.g., of war or of deterrence success), since enough other deterrents already exist, because of the choice of the values at which they are set. We have therefore set the variables at relatively low values to better assess the effects of individual variables.
For example, the "minimal" case is one where the defender does not possess nuclear weapons, where the attacker has twice as many forces (immediate, short-term, as well as long-term) as the defender-protege, where no military alliance exists between the defender and protege, where military arms transfers and foreign trade between the defender and protege are very low, where a firm-butflexible diplomatic and a tit-for-tat military bargaining strategy were not used by the defender, where the last encounter between the attacker and defender did not end in a stalemate, and where neither the attacker nor the defender are democracies. The "minimal" case is one where we would not usually expect the attacker to be deterred. For precisely that reason, it is interesting to ask, whether possession of nuclear weapons, stationing more forces along the front, or military alliances, for example, would be enough to deter potential attackers in this scenario. The "low" case is similar to the "minimal" one, with the exception that the defender-protege forces are now threefourths (rather than only half) those of the attacker's, and there is slightly greater foreign trade and arms transfers between defender and protege. The "moderate" case shifts the balance of forces even more in favor of the defender and protege, and significantly increases their arms transfers and foreign trade as well.

In the following discussion, we will start with Table 3 for the effects of the binary variables, and then move on to the continuous variables. ${ }^{17}$ Table 3 displays the probability of deterrence success (labeled "Deter") and the probability of war (labeled "War"). ${ }^{18}$ The first row in the table shows the probabilities calculated for each of the "baseline" cases, i.e., where each of the variables are set at the "minimal," "low," and "moderate" values. (Note from Table 2 that the binary variables are all set to zero in each of the baseline cases.) The lower rows display the probabilities when the row variable is set to one, and all other variables are held at the baseline values. The effect of a row variable is therefore simply the difference between the row probability and the baseline probability.

Before proceeding to the individual variables, we should examine what the baseline cases represent in terms of the model's estimated probabilities. Take the "minimal" case, where the balance-of-forces are decidedly in favor of the attacker. In this situation, the defender has

\footnotetext{
${ }^{17}$ Due to space constraints, we limit the discussion in this section to a subset of substantively interesting results. A discussion of the other variables is available in the supplement to this paper, which can be downloaded from the aforementioned website.
${ }^{18}$ Since deterrence success is equivalent to the status quo outcome, the probability that the defender capitulates can be determined at war, and subtracting that from one. any time by adding the probabilities of deterrence success and of
} 
TABLE 3 Effects of Binary Variables

\begin{tabular}{|c|c|c|c|c|c|c|}
\hline & \multicolumn{6}{|c|}{ Holding All Other Variables at } \\
\hline & \multicolumn{2}{|c|}{ Minimal } & \multicolumn{2}{|c|}{ Low } & \multicolumn{2}{|c|}{ Moderate } \\
\hline & Deter & War & Deter & War & Deter & War \\
\hline Baseline: & & & & & & \\
\hline $\begin{array}{l}\text { Binary } \\
\quad \text { Variables }=0\end{array}$ & 0 & .02 & 0 & .96 & .76 & .24 \\
\hline $\begin{array}{l}\text { Individual } \\
\qquad \text { Variable }=1\end{array}$ & & & & & & \\
\hline Nuclear & 0 & .99 & .24 & .76 & 1 & 0 \\
\hline Military Alliance & 0 & .99 & 0 & 1 & 0 & 1 \\
\hline Tit-for-Tat & 0 & .02 & 1 & 0 & 1 & 0 \\
\hline FirmFlex & 0 & .02 & 0 & .96 & 1 & 0 \\
\hline Stalemate & 0 & .99 & 0 & 1 & .76 & .24 \\
\hline Dem. Defender & 0 & .98 & 0 & 1 & .76 & .24 \\
\hline Dem. Attacker & 0 & .02 & .99 & 0 & 1 & 0 \\
\hline
\end{tabular}

little hope of winning a war, and so will almost certainly capitulate. The attacker knows (or believes) this and will therefore attack. The model's resulting probability of deterrence success is $\operatorname{Pr}($ Deter $) \approx 0$ and the probability of war is $\operatorname{Pr}(W a r)=.02$. This, of course, implies that the probability that the defender capitulates is $\operatorname{Pr}($ Cap $)=.98$. Given the lack of deterrents in this situation, an obvious question to ask in the subsequent analysis is whether any individual factor (e.g., nuclear weapons) would by itself be a sufficient deterrent. Similarly, we will examine whether any individual factor makes the defender more likely to defend the protege.

In the "low" case, the defender and protege are still at a disadvantage in terms of the balance of forces, but not nearly as much as in the "minimal" scenario. As see from Table 3, the results suggest that the attacker is still not deterred $(\operatorname{Pr}($ Deter $) \approx 0)$. However, the increased balance of forces make it much more likely that the defender will come to the aid of the protege, resulting in a high likelihood of war $(\operatorname{Pr}(W a r)=.96)$. In the "moderate" situation, the balance has shifted in favor of the defender-protege, but not overwhelmingly. In this case, the attacker will be deterred with fairly high probability $(\operatorname{Pr}($ Deter $)=.76)$, the defender will certainly defend its protege, and war will result with probability .24 .

Taking these three cases together, one interesting result is that increasing the balance of forces has a nonmonotonic effect on the the likelihood of war-in other words, arming the defender and protege does not always lead to an increased likelihood of peace. When the defender and protege are severely disadvantaged, arming them may make them more likely to fight without simultaneously deterring the attacker, resulting in an increased probability of war. It is only after the defender and protege are sufficiently well armed that further arming them deters the attacker and thus decreases the likelihood of war. Note that this kind of dynamic is extremely difficult to capture in a nonstrategic statistical model, e.g., probit analysis, in which the attacker and defender's decisions cannot be modeled in an integrated way. Having examined the "baseline" situations, we now examine the effects of the individual variables, beginning with nuclear weapons.

Nuclear Weapons. Scholars have come to very different conclusions concerning the effect of nuclear weapons on deterrence success-and on international stability more broadly. Some conclude that possessing nuclear weapons increases the likelihood of deterrence success (e.g., Alexandroff and Rosencrance 1977; Fearon 1994a; Huth 1990; Huth, Gelpi, and Bennett 1993; Waltz 1990; Weber 1990). Others conclude that nuclear weapons have no effect at all (e.g., Huth 1988; Mueller 1989; Paul 1995). Finally, Waltz (1981) argues that either no proliferation or a relatively fast proliferation of nuclear weapons increases the chance of war.

As seen from Table 3, our results indicate that the general effect of the defender's possession of nuclear weapons is to increase the probability of deterrence success. It does so for two reasons. As we saw in Table 1, possession of nuclear weapons is associated with a higher defender utility for war, and hence makes it more likely to defend. It is also associated with a decrease in the attacker's utility for war. Because possession of nuclear weapons simultaneously increases the probability that the defender will fight and decreases the attacker's utility for war, the attacker's expected utility for attacking decreases, making it more likely that the attacker will be deterred. As seen in Table 3, this holds for all of the cases (minimal, low, and moderate), although the effect in the "minimal" case is negligible.

The effect of a nuclear capability on the likelihood of war is slightly more complicated. Whereas the defender's possession of nuclear weapons is associated with a monotonic increase in the likelihood of deterrence success, it has a nonmonotonic effect on the likelihood that war will occur, and for essentially the same reason as discussed before. In the "minimal" situation, when the defender does not possess nuclear weapons, the situation so favors the attacker that the defender will capitulate $(\operatorname{Pr}($ Cap $)=.98)$. The attacker knows (or believes) this, and so the attacker is not deterred $(\operatorname{Pr}($ Deter $)=0)$. The resulting probability of war is extremely small (.02). However, if the defender now possesses nuclear weapons, it is much more likely to 
defend, but the attacker (whom the conventional balance of forces favors quite strongly) is not yet deterred. Therefore, the probability of war is very high.

In the "low" case, without nuclear weapons, the conventional balance of forces is such that the defender is very likely to defend, but the attacker is not yet deterred. Therefore, the probability of war is very high. If the defender possesses nuclear weapons in this scenario, its probability of defending jumps moderately from .96 to 1 . Because this is also associated with a decrease in the attacker's utility for war (which is now certain if the attacker attacks the protege), the probability of deterrence success increases from 0 to .24 (meaning that the attacker is still willing to attack with probability .76), resulting in a significant decrease in the probability of war. A very similar dynamic occurs in the "moderate" case, in which the conventional balance of forces slightly favors the defenderprotege. The main difference in this situation is that the attacker is quite likely to be deterred even when the defender does not possess nuclear weapons, and the defender is certain to defend. The effect of a nuclear defender in this scenario is to decrease the probability of war from .24 to essentially zero, because the attacker is sure to be deterred.

Our results suggest, then, that nuclear weapons will (1) generally incline the defender to assist its protege, (2) generally increase the probability of deterrence success, but (3) depending on the values of the other variables, may increase or decrease the likelihood of war. Indeed, one of the main values of this analysis is that it illustrates that certain independent variables may have nonmonotonic or only conditionally monotonic effects on the dependent variable, a dynamic that is extremely difficult to capture using nonstrategic statistical models, e.g., probit.

Tit-for-Tat, Firm-but-Flexible, Democratic Attacker. Our results indicate that the defender's use of a tit-fortat military preparations strategy, as well as "firm-butflexible" diplomatic bargaining, are associated with an increase in the attacker's utility for the status quo. Also, we find that democratic attackers generally have higher utilities for the status quo than do authoritarian attackers, other things equal. Any factor that is associated with an increase in the attacker's utility for the status quo must, by definition, lead to an increase in the probability of deterrence success and therefore a decrease in the probability of war. Indeed, Table 3 reflects exactly that. Notice, however, that tit-for-tat military preparations appear to have more of an effect than firm-but-flexible diplomatic bargaining. Neither has much of an effect in the "minimal" situation, in which the balance of forces so favor the attacker that it attacks regardless. In the "low" case, tit-fortat military preparations have a huge deterrent effect (and therefore dramatically decreases the probability of war as well), while a firm-but-flexible diplomatic strategy has no discernible effect at all. In the "moderate" case, both variables are associated with a significant increase in the probability of deterrence success, and therefore a significant decrease in the probability of war. The results suggest that when the balance of forces are not overwhelmingly in the attacker's favor, firm-but-flexible diplomatic bargaining, and especially tit-for-tat military preparations, can significantly increase the likelihood of deterrence success by conveying resolve to the attacker while not putting its reputation and credibility on the line.

The dynamic for the democratic attacker variable is similar. It has no effect in the "minimal" situation, where the attacker attacks regardless. In the "low" and "moderate" cases, where the balance of forces are more in favor of the defender-protege, the democratic attacker variable is associated with an increase in the probability of deterrence success, and hence a decrease in the likelihood of war. Interestingly, the results thus suggest that when the balance of forces are overwhelmingly in favor of the attacker, its regime type is not very important-it attacks regardless. This suggests that the pacifying effect of democratic government may be mitigated by balance-of-force considerations.

Immediate and Short-Term Balance of Forces. The effects of the immediate and short-term balance of forces, which are continuous variables, are displayed in Figure $3(\mathrm{a}-\mathrm{d})$. The probability of deterrence success and of war are plotted as a function of $I B F$ and $S B F$, holding all the other variables constant at their "minimal" (dotted lines), "low" (dashed lines), and "moderate" (solid lines) values.

Recall from Table 1 that we find that an increase in either the immediate or short-term balance of forces is associated with (1) an increase in the defender's utility for war, making it more likely to defend the protege, and (2) a decrease in the attacker's utility for war, making it less likely to attack. As seen in Figures 3(a) and (c), this results in a monotonic effect on the probability of deterrence success: an increase in either the immediate or short-term balance of forces in favor of the defender-protege is always associated with an increase in the probability of deterrence success. This is a fairly intuitive result: the more soldiers the defender and protege have on the front line and in reserve, the less likely the attacker is to attack. Huth (1988) also finds that these variables increase the probability of deterrence success. 


\section{FIGURE 3 Effect of Immediate and Short-Term Balance of Forces}

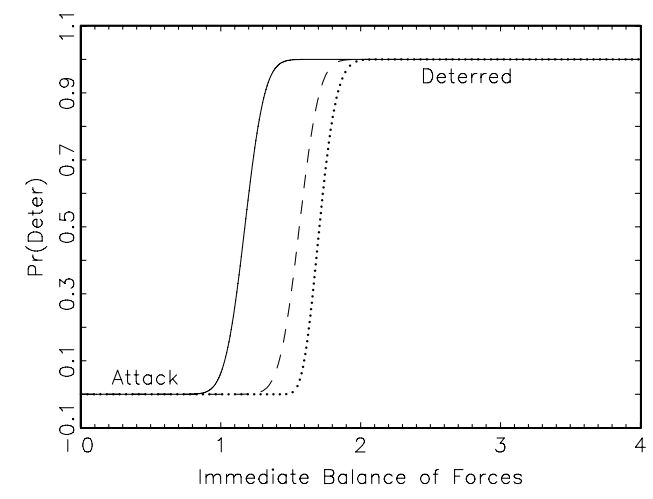

(a) Effect of IBF on Deterrence Success

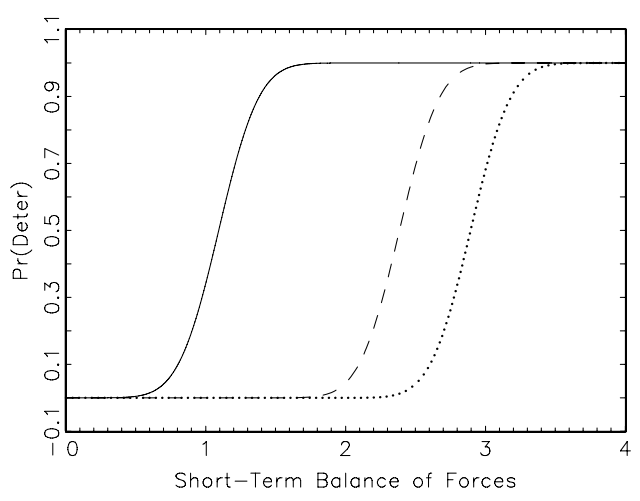

(c) Effect of SBF on Deterrence Success

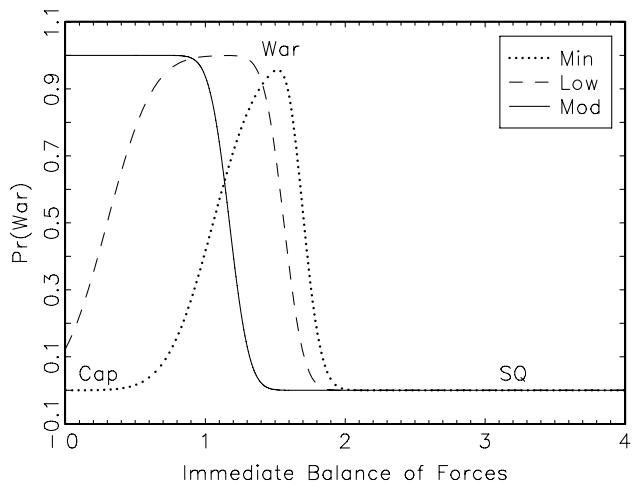

(b) Effect of IBF of War

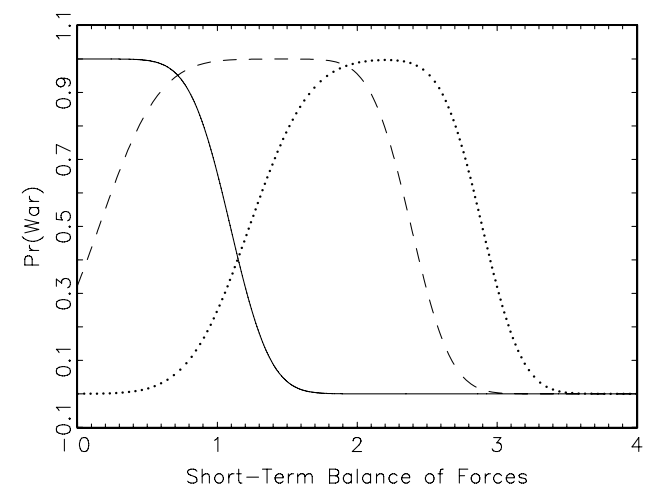

(d) Effect of SBF on War
Examining Figures 3(a) and (c), two other interesting results emerge. First, the point at which the immediate and short-term balance of forces have the greatest effect-i.e., result in the largest change in the probability-depends on the values at which the other variables are held constant. Consider the "minimal" situation, when most other factors favor the attacker. To deter the attacker with high probability, the defender and protege need to increase the immediate balance of forces to almost twice that of the attacker (i.e., $I B F=2$ ), or increase the short-term balance of forces to over three times the attacker's. When other deterrent factors are more favorable for the defender and protege, fewer soldiers on the front line and in reserve are required to deter the potential attacker. For example, in the "moderate" scenario, the defender-protege require only a little over parity in the immediate balance to deter the attacker, or only about 1.5 times the attacker's shortterm forces. With an additional deterrent factor or two, even less of an advantage in the balance of forces would be required.
The second result that jumps out of Figures 3(a) and (c) concerns the relative impact of the immediate and short-term balance of forces. The graphs show that the immediate balance generally has a greater deterrent effect, in the sense that fewer soldiers on the front are required to deter the attacker, relative to soldiers in reserve (this is most obvious in the "minimal" and "low" situations).

Figures 3(b) and (d) display the effect of the immediate and short-term balance of forces on the probability of war between the attacker and the defender. The figures indicate that both variables have a nonmonotonic effect on the probability of war. The intuition is fairly straightforward. Consider the "minimal" situation (the dotted line) in Figure 3(b). When the immediate balance of forces greatly favors the attacker (e.g., when $I B F<.8$ ), the defender will likely capitulate if the protege is attacked. The attacker knows (or believes) this and therefore attacks. Capitulation results with near certainty, and the probability of war is near zero. As the immediate balance of forces increases in favor of the defender-protege, the defender 
is more likely to defend, but the attacker is not yet being deterred. Therefore, the probability of war increases. It is only when the immediate balance of forces increases to about 1.5 that the deterrent effect starts kicking in, and hence the probability of war starts decreasing.

\section{Historical Examples}

Statistical research is often reported without reference to specific cases in the data. An argument for this is that the purpose is to find trends in the data, rather than to explain any individual event. While we are sympathetic to that perspective, we would also like to examine the predicted effects of particular variables in actual cases in the data, and to perform counterfactual analysis to see what the results predict about how certain prominent international crises could have otherwise turned out. Therefore, we examine the model's predictions with regard to the 1948 Berlin Blockade, a crisis that most students of international relations are very familiar with, as well as a less-known crisis, the Soviet-Japanese conflict over Manchukuo. We focus on the effects of the immediate and short-term balance of forces, as well as nuclear weapons (when they existed).

\section{Soviet Crisis with Japan over Manchukuo, 1937-1938}

In June 1937, Soviet forces captured islands in a branch of the Amur River marking the border between the Soviet Union and the Japanese puppet state of Manchukuo (formerly Manchuria) in northeast China. Japan moved troops to the area and demanded that the Soviet forces leave the islands. Of significance is the fact that Japan matched the Soviets in terms of forces in that area, sending divisions from Japan's elite Kwantung Army (Ikuhiko 1976, 137-38). Although the Soviets held an advantage in terms of overall armed forces, they were deterred at that time from their attempt to alter the border, and they subsequently left the islands.

Just one year later (July 1938), the Soviet Union sent troops to occupy Changkufeng, a strategic hill on the disputed Soviet-Korean-Manchukuo border. Japan, with its troops now bogged down in a war against China, was either not willing or able to match the number of troops committed by the USSR to the dispute. It has been argued that Japan deliberately limited the number of troops because it wanted to keep the conflict localized and not lead to a broader war with the USSR, while already engaged in a war against China (Blumenson 1960, 263; Coox 1976,
121; Ikuhiko 1976, 142). Japan subsequently committed 10,000 troops, compared with the USSR's 20,000 (Blumenson 1960, 262; Ikuhiko 1976, 154). In contrast to the events one year before, deterrence failed. The Soviets refused to back down from their demand for a change in the border. The Japanese leadership decided to defend the region, and war ensued.

Interestingly, these two cases nicely form a kind of "natural experiment" in the data. As it turns out, the values of all of the explanatory variables for the two observations are virtually the same, with the exception of the immediate and short-term balance of forces. In 1937, $I B F=1$ and $S B F=.43$, whereas in $1938, I B F=.5$ and $S B F=.36$. Although the short-term balance increased slightly in the USSR's (the attacker's) favor, what really differed between these events was the immediate balance of forces.

Figure 4 plots the model's estimated probability of deterrence success as a function of the immediate and short-term balance of forces, holding all other variables at their 1937/1938 values. ${ }^{19}$ The estimated probabilities using the actual data for those two crises are denoted by the two thick dots on the surface and the year labels next to them (i.e., these are the actual values of $I B F$ and $S B F$ in these two crises). As the figure shows, the model makes strong predictions about the probability of deterrence success in these two situations. For the 1937 crisis, the model correctly predicts that the Soviets would almost certainly be deterred. The exact opposite is predicted for the 1938 crisis. Although it cannot be shown in the figure, the model also correctly predicts war in the 1938 crisis with probability .97 .

The estimated results also allow us to perform counterfactual analysis within the context of the model. The dark lines on the surface of the graph in Figure 4 plot the predicted probability of deterrence success as the immediate and short-term balance of forces are individually changed from the 1937 and 1938 values. ${ }^{20}$ First consider the 1937 crisis. Figure 4 suggests that if Japan had not matched the USSR in troops sent to the region (i.e., if $I B F$

\footnotetext{
${ }^{19}$ The graph denotes the estimated probability based on regression results when the 1937/1938 cases are excluded from the data set, i.e., based on a regression result with 56 observations. Hence, this is effectively an out-of-sample prediction. We do the same with the Berlin Blockade, which is analyzed next, i.e., we plot the graphs using regression results when that case is excluded from the data set. The estimated regression coefficients when these cases are excluded from the data set are very similar to the reported ones (based on all observations) in Table 1. Hence, the graphs of the predicted probabilities if we analyze these as in-sample predictions look virtually identical to the out-of-sample ones that we present.
}

${ }^{20}$ Of course, we could also assess the effect of changing both variables simultaneously. However, researchers are usually interested in analyzing the effect of individual variables. 


\section{FIGURE 4 Japan's Deterrence of the Soviet Union over Manchukuo, 1937 and 1938}

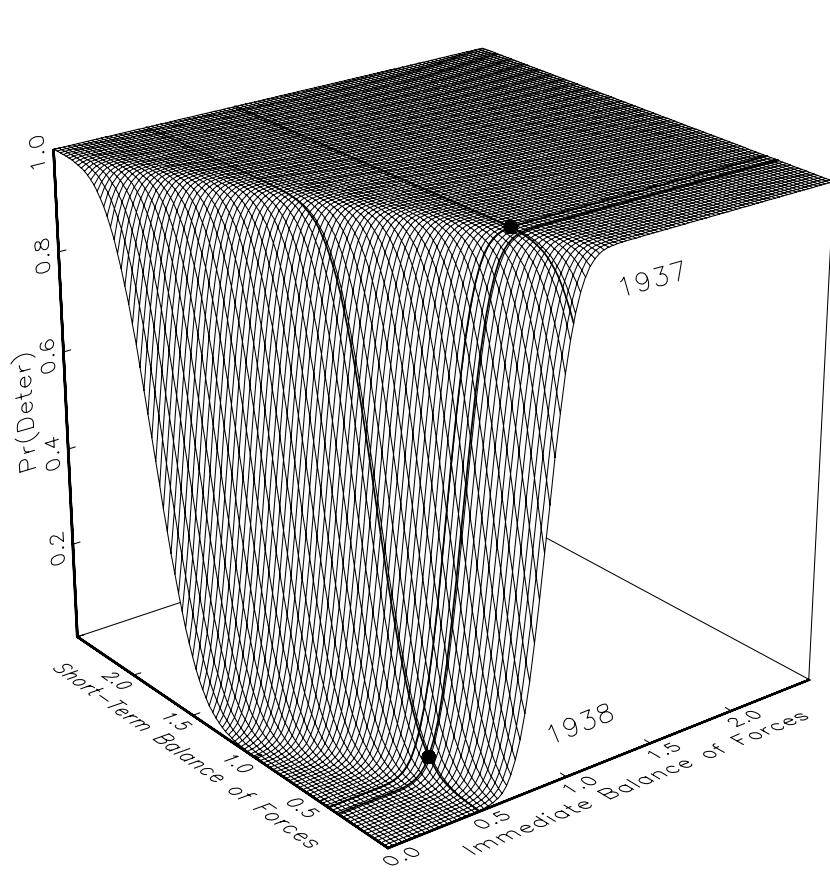

was lower than 1), then the Soviets would not have been deterred from attempting to alter the Soviet-Manchukuo border. As the immediate balance changes from parity $(I B F=1)$ to a 2:1 advantage for the Soviets (i.e., $I B F=.5)$, the predicted probability of deterrence success decreases from nearly one to nearly zero. The figure also suggests that the immediate balance was much more important in this case than the short-term balance: increasing the short-term balance even more in the Soviets' favor (whom it strongly favored anyway) only moderately decreases the predicted probability of deterrence success, given that Japan matched the Soviet commitment of troops at the front.

Turning to the 1938 crisis, our results predict that if Japan had been willing to match the Soviet commitment of front-line troops as it had in 1937 (i.e., if $I B F \geq 1$ ), then the Soviets would have likely backed down from their demand to alter the border. Interestingly, Blumenson (1960, 250) argues that the Soviets were not prepared for a fullfledged war with Japan and would have backed down if Japan had been willing to commit more resources to the dispute. He further speculates (255) that the Soviets deliberately timed their demand for a border change at a time when Japanese troops were bogged down in the war against China. In contrast to the 1937 crisis, the results also suggest that the short-term balance could have played a more decisive role in 1938. Although this would have required a tremendous (and perhaps impossible) effort by Japan, it can be seen from Figure 4 that our results suggest that a massive increase in Japan's overall armed forces (i.e., $S B F)$ to at least a 3:2 advantage $(S B F \geq 1.5)$ over the Soviets would have deterred the latter, even without any corresponding increase in the number of troops sent to the actual disputed area. But a mere parity in the immediate balance would have been enough to deter the Soviets, suggesting that troops at the front play a more significant role in achieving deterrence success.

\section{Berlin Blockade, 1948}

There has been quite some dispute regarding the role that the US's nuclear capability played in the 1948 Berlin Blockade crisis. Among the detractors, Betts (1987) argues that the United State's threats to use nuclear weapons against the Soviet Union were vague and ambiguous, and their impact on the final outcome was unclear. More recently, Gaddis $(1997,91,98)$ has also argued that the United State's threats were vague. For example, he points out that although B-29 "atomic bombers," the type that had dropped the atomic weapons on Hiroshima and Nagasaki, were sent to Britain and Germany, these particular ones were not nuclear-capable, and their impact on the outcome was uncertain. In contrast to these two analyses, our results suggest that the United State's possession of nuclear weapons played a very significant role in deterring the Soviet Union from escalating the crisis.

Figures 5(a) and (b) display the predicted probabilities of deterrence success and war, respectively, for this case, as a function of the immediate and short-term balance of forces. The probabilities are plotted over a range of values for the immediate and short-term balance of forces, with the thick dot on the surface of the graphs marking the actual values of $I B F$ and $S B F$ in the crisis. As seen in Figure 5(a), the results correctly predict deterrence success with probability $p_{s q} \approx 1$-i.e., that the Soviets would not seriously challenge the Allied airlift and would eventually end the ground blockade without further escalating the crisis. In this case, the USSR held a 10:1 advantage in the immediate balance of forces over the US (IBF = .1). These forces were in a position to immediately engage in battle over Berlin, which of course lay in the Soviet zone of Germany that would eventually become East Germany. Additionally, the Soviet Union held a large advantage in the short-term balance of forces $(S B F=.34)$. The U.S. defense budget was quite low at the time, and its conventional forces very weak (Betts 1987, 28; Gaddis 1997, 91; Oneal 1982, 248, 257-59). 


\section{FIGURE 5 Effect of Immediate Balance of Forces, Short-Term Balance of Forces, and Nuclear Weapons in Berlin Blockade (1948)}

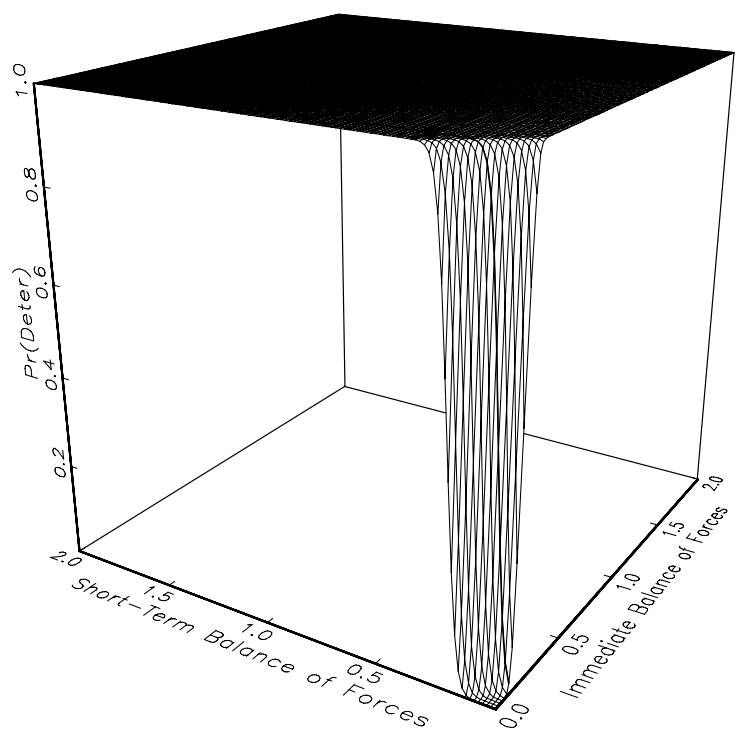

(a) Probability of deterrence success, based on actual data

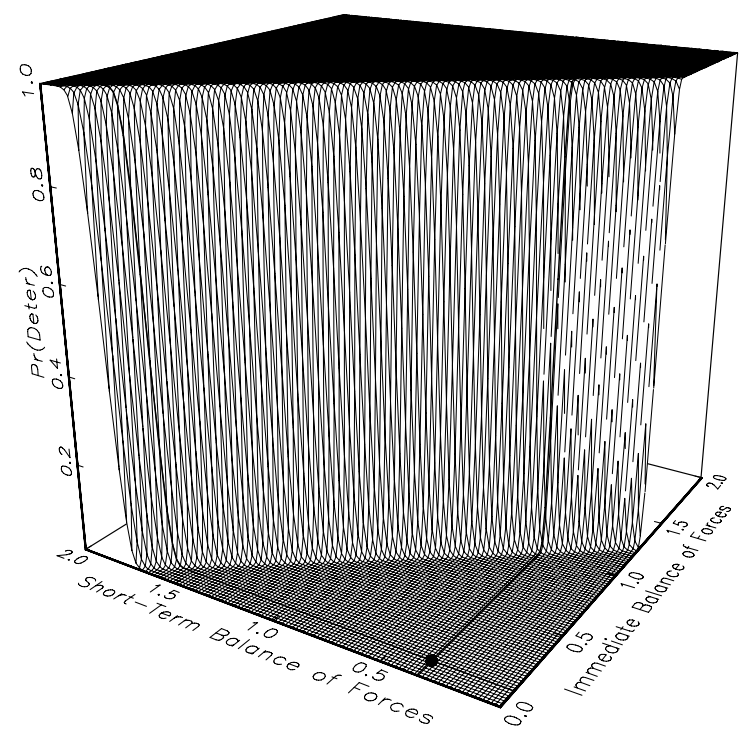

(c) Probability of deterrence success, assuming non-nuclear US

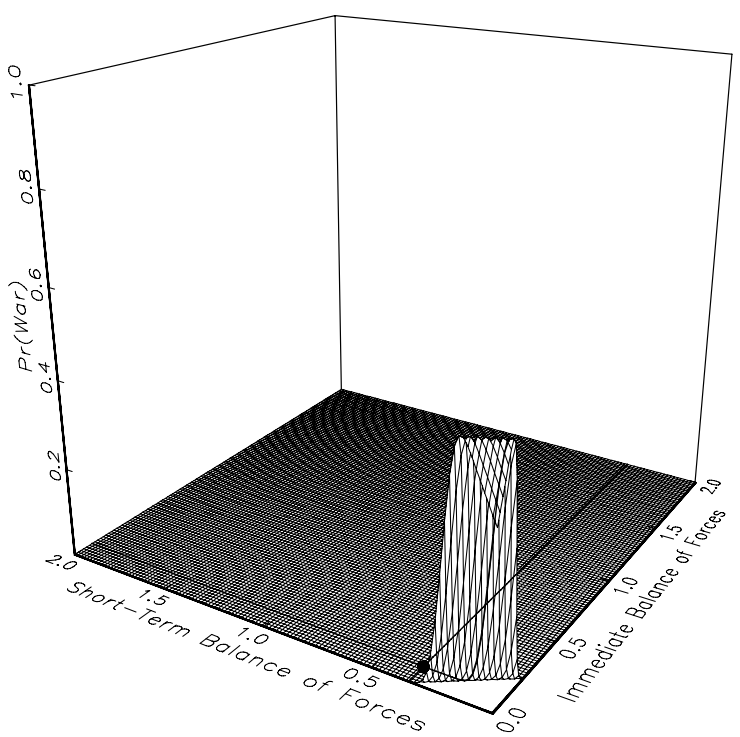

(b) Probability of war, based on actual data

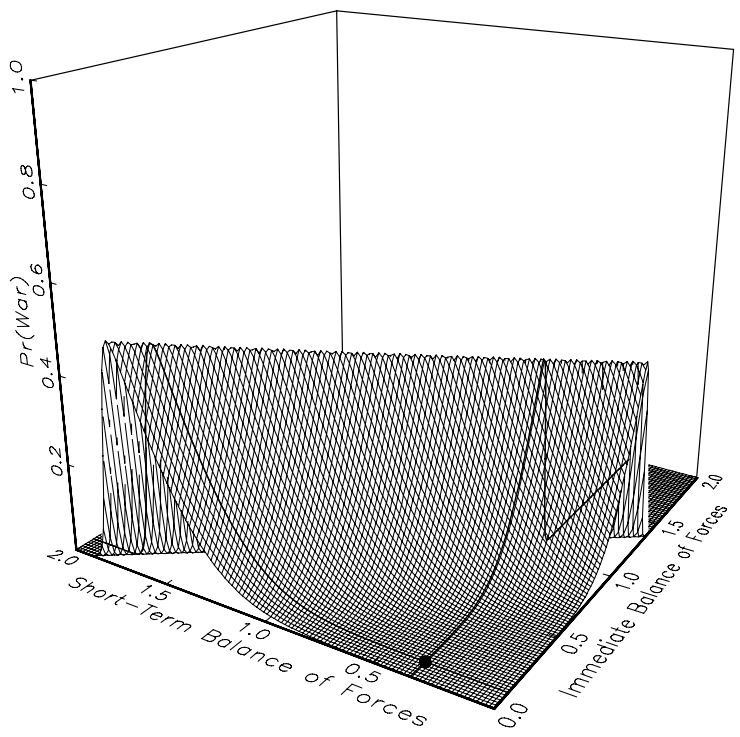

(d) Probability of war, assuming non-nuclear US
Referring again to Figure 5(a), the model predicts that the USSR would have been deterred even if the immediate balance of forces was even more in its favor (i.e., if $I B F$ was even lower). This makes sense, given that the Soviets could have quite easily overwhelmed the allied forces in Berlinit is unlikely that the military capability of the allied forces in Berlin played a deterrent role. However, if the number of its standing armed forces was even higher relative to the United States (i.e., if $S B F$ was even lower), the predicted probability that the USSR would have been deterred drops dramatically, despite the fact that the United States possessed nuclear weapons. That is to say, the model predicts 
that if the United State's conventional forces were completely trivial compared to the USSR's, the Soviets would not have been deterred, despite the fact that the United States possessed nuclear weapons. As seen in Figure 5(b), the predicted probability of war therefore rises, although not too much, because the United States would have been less likely to defend Berlin as the short-term balance of forces increasingly favored the USSR.

Provocatively, the model predicts that if the United States did not have nuclear weapons, the probability of deterrence success would have dropped to virtually zero, and with probability $p_{c a p} \approx 1$ the United States would have surrendered Berlin. This is seen in Figures 5(c) and (d), which display the predicted probabilities of deterrence success and war, respectively, in the counterfactual scenario in which the United States did not possess nuclear weapons. That is, Figures 5(c) and (d) are generated in exactly the same manner as Figures 5(a) and (b), except that the variable NUCLEAR is set to 0 (its counterfactual value) rather than 1 (its true value; all other variables are held at their actual values). Gaddis $(1997,92)$ also speculates that if the United States did not possess nuclear weapons, it is possible that it would not have even attempted an airlift in support of Berlin against the Soviets, given the USSR's great superiority in the conventional balance of forces (also see Betts 1987, 24).

As seen in Figure 5(c), our results suggest that it would have taken a nonnuclear United States a little over parity in the immediate balance of forces to deter the USSR, or alternatively just over a 3:2 advantage in the standing armed forces. In other words, if the United States did not possess nuclear weapons, it would have taken an enormous increase in the immediate or short-term conventional balance of forces (over their actual values) to deter the USSR from escalating the crisis.

In some ways, the likelihood of war is also greater in this counterfactual scenario. Consider Figure 5(d). The predicted probability of war initially increases as $I B F$ or $S B F$ increase over their actual values, because the United States would have been more likely to defend Berlin as the balance of forces increased in its favor (and the USSR is at this point not yet deterred). Although the predicted probability of war begins declining once $I B F$ increases beyond about 1 or $S B F$ increases beyond about 1.5 (because the Soviets are more likely to be deterred), there exists a much larger range of values of $I B F$ and $S B F$ for which the probability of war is positive in the counterfactual scenario than in the actual scenario. Comparing these graphs to those in Figures 5(a) and (b), it can be seen that our results suggest that (1) nuclear weapons played a critical role in deterring the USSR, and (2) lack of nuclear weapons would have left more "room" for war.

\section{Concluding Remarks}

In this paper, we present the first unified theory and statistical test of extended immediate deterrence. Previous empirical studies of deterrence have used nonstrategic statistical models (e.g., probit), even though the rational deterrence literature always portrays deterrence as a strategic interaction between potential attacker and defender. Recent methodological work suggests that using a nonstrategic statistical model to analyze data believed to be generated by a strategic process can lead to very misleading inferences.

In terms of substantive findings, we find that in contrast to Huth (1988), military alliances, the long-term balance of forces, nuclear weapons, military arms transfers, and foreign trade all affect deterrence success. In contrast to Huth and Russett (1988), we find that the latter three variables, as well as the immediate balance of forces, influence the defender's decision to defend its protege. We find that an actor's regime type can influence the deterrence calculus in a way that is generally consistent with the theory of audience costs (e.g., Fearon 1994b; Schelling 1960), but that balance-of-force considerations can overwhelm the effect of regime type. We also illustrate how the results of a statistical strategic analysis can be used to perform counterfactual analysis in actual cases.

Importantly, we also find that many of the explanatory variables often hypothesized to influence deterrence success or failure are nonmonotonically, or only conditionally monotonically, linked to the likelihood of deterrence success or war. This has very important methodological implications, because nonstrategic statistical models such as probit, which are the norm in the international relations literature, face severe difficulties in capturing such relationships (and to the extent that they can do so, it is usually in arbitrary ways, e.g., by squaring or cubing the explanatory variables). The analysis we present here offers compelling arguments that statistical models in international relations should, whenever possible, be explicitly derived from the underlying theoretical model.

Having said that, there are important ways in which this analysis can be improved on in future research. The most important issue in this regard is that we have not modeled the entire deterrence interaction, and therefore selection effects may be influencing our results. Most of our substantive findings make intuitive sense, but there are a couple of anomalous findings that may be due to selection effects. In order to statistically estimate the entire deterrence interaction, a significant data collection effort would be needed. In the immediate deterrence subgame, there are only three outcomes. In the entire 
deterrence interaction, there would be significantly more (e.g., Fearon 1994a), which would require a large number of observations in order for a robust statistical analysis to be possible.

\section{References}

Achen, Christopher H., and Duncan Snidal. 1989. "Rational Deterrence Theory and Comparative Case Studies." World Politics 41(2):143-69.

Alexandroff, Alan, and Richard Rosencrance. 1977. "Deterrence in 1939." World Politics 29(3):404-24.

Bennett, D. Scott, and Allan Stam. 2000. "EUGene: A Conceptual Manual.” International Interactions 26(2):179-204.

Betts, Richard K. 1985. "Conventional Deterrence: Predictive Uncertainty and Policy Confidence." World Politics 37(2):153-79.

Betts, Richard K. 1987. Nuclear Blackmail and Nuclear Balance. Washington: Brookings.

Blumenson, Martin. 1960. "The Soviet Power Play at Changkufeng." World Politics 12(2):249-63.

Bueno de Mesquita, Bruce. 1981. The War Trap. New Haven: Yale University Press.

Coox, Alvin D. 1976. "Introduction to 'The Japanese-Soviet Confrontation, 1935-1939'.” In Deterrent Diplomacy: Japan, Germany and the USSR, 1935-1940, ed. James William Morley. New York: Columbia University Press, pp. 11527.

Danilovic, Vesna. 2001. "Conceptual and Selection Bias Issues in Deterrence." Journal of Conflict Resolution 45(1):97-125.

Fearon, James D. 1994a. "Signaling Versus the Balance of Power and Interests: An Empirical Test of a Crisis Bargaining Model." Journal of Conflict Resolution 38(2):236-69.

Fearon, James D. 1994b. "Domestic Political Audiences and the Escalation of International Disputes." American Political Science Review 88(3):577-92.

Gaddis, John Lewis. 1997. We Now Know: Rethinking Cold War History. Oxford: Oxford University Press.

George, Alexander, and Richard Smoke. 1974. Deterrence in American Foreign Policy. New York: Columbia University Press.

Hopf, Ted. 1994. Peripheral Vision: Deterrence Theory in American Foreign Policy in the Third World: 1965-1990. Ann Arbor: University of Michigan Press.

Huth, Paul K. 1988. Extended Deterrence and the Prevention of War. New Haven: Yale University Press.

Huth, Paul K. 1990. "The Extended Deterrent Value of Nuclear Weapons." Journal of Conflict Resolution 34(2):270-90.

Huth, Paul K., and Bruce Russett. 1984. "What Makes Deterrence Work? Cases from 1900 to 1980." World Politics 36(4):496-526.

Huth, Paul K., and Bruce Russett. 1988. "Deterrence Failure and Crisis Escalation.” International Studies Quarterly 32(1):29_ 45.

Huth, Paul K., and Bruce Russett. 1990. “Testing Deterrence Theory: Rigor Makes a Difference.” World Politics 42(4):466501.
Huth, Paul K., and Bruce Russett. 1993. "General Deterrence Between Enduring Rivals: Testing Three Competing Models." American Political Science Review 87(1):61-73.

Huth, Paul, Christopher Gelpi, and D. Scott Bennett. 1993. "The Escalation of Great Power Militarized Disputes: Testing Deterrence Theory and Structural Realism." American Political Science Review 87:609-23.

Ikuhiko, Hata. 1976. "The Japanese-Soviet Confrontation, 1935-1939." In Deterrent Diplomacy: Japan, Germany and the USSR, 1935-1940, ed. James William Morley. New York: Columbia University Press, pp. 129-78.

Jaggers, Keith, and Ted Robert Gurr. 1996. "Polity III: Regime Change and Political Authority, 1800-1994.” [computer file]. 2d ICPSR ed. Study no. 6695. Ann Arbor, Mich.: InterUniversity Consortium for Political and Social Research. $<$ www.icpsr.umich.edu $>$.

Kilgour, D. Marc, and Frank C. Zagare. 1991. "Credibility, Uncertainty, and Deterrence." American Journal of Political Science 35(2):305-34.

Kugler, Jacek, and Frank C. Zagare. 1987. Exploring the Stability of Deterrence. Boulder: University of Denver Press.

Langlois, Jean-Pierre P. 1991. "Rational Deterrence and Crisis Stability.” American Journal of Political Science 35(4):80132.

Lewis, Jeffrey B., and Kenneth A. Schultz. 2003. "Revealing Preferences: Empirical Estimation of a Crisis Bargaining Game with Incomplete Information.” Political Analysis 11(4):34567.

Mearsheimer, John. 1983. Conventional Deterrence. Ithaca: Cornell University Press.

Morgan, Patrick M. 1983. Deterrence: A Conceptual Analysis. 2nd ed. Beverly Hills: Sage.

Mueller, John. 1989. Retreat from Doomsday: The Obsolescence of Major War. New York: Basic Books.

Oneal, John R. 1982. Foreign Policy Making in Times of Crisis. Columbus: The Ohio State University Press.

Paul, T. V. 1995. "Nuclear Taboo and War Initiation in Regional Conflicts." Journal of Conflict Resolution 39(4):696717.

Powell, Robert. 1990. Nuclear Deterrence Theory. Cambridge: Cambridge University Press.

Rich, Norman. 1992. Great Power Diplomacy: 1814-1914. Boston: McGraw-Hill.

Rousseau, David L., Christopher Gelpi, Dan Reiter, and Paul K. Huth. 1996. "Assessing the Dyadic Nature of the Democratic Peace, 1918-1988." American Political Science Review 90(3):512-33.

Schelling, Thomas C. 1960. The Strategy of Conflict. Cambridge: Harvard University Press.

Schultz, Kenneth A. 1999. "Do Democratic Institutions Constraint or Inform? Contrasting Two Institutional Perspectives on Democracy and War." International Organization 53(2):233-66.

Signorino, Curtis S. 1999. "Strategic Interaction and the Statistical Analysis of International Conflict." American Political Science Review 93(2):279-97.

Signorino, Curtis S. 2003. "Structure and Uncertainty in Discrete Choice Models." Political Analysis 11(4):31644. 
Signorino, Curtis S., and Kuzey Yilmaz. 2003. "Strategic Misspecification in Regression Models." American Journal of Political Science 47(3):551-66.

Smith, Alastair. 1996. "To Intervene or Not to Intervene: A Biased Decision." Journal of Conflict Resolution 40(1):1640.

Taylor, A.J.P. 1954. The Struggle for Mastery in Europe: 18481918. Oxford: Oxford University Press.

Waltz, Kenneth. 1981. "The Spread of Nuclear Weapons: More May Be Better." Adelphi Papers. London: International Institute for Strategic Studies.

Waltz, Kenneth. 1990. "Nuclear Myths and Political Realities." American Political Science Review 84(3):731-45.
Weber, Steve. 1990. "Realism, Detente, and Nuclear Weapons." International Organization 44(1):55-82.

Werner, Suzanne. 2000. "Deterring Intervention: The Stakes of War and Third-Party Involvement." American Journal of Political Science 44(4):720-32.

Wu, Samuel S. G. 1990. "To Attack or Not to Attack: A Theory and Empirical Assessment of Extended Immediate Deterrence." Journal of Conflict Resolution 34(3):53152.

Zagare, Frank C., and D. Marc Kilgour. 1993. "Asymmetric Deterrence." International Studies Quarterly 37(1):1-28.

Zagare, Frank C., and D. Marc Kilgour. 2000. Perfect Deterrence. Cambridge: Cambridge University Press. 